\title{
Kantil regresyon ile gövde çapı modelinin geliştirilmesi
}

\author{
Ramazan Özçelik' ${ }^{a}$, Onur Alkan”,* (iD, Şerife Kalkanlı ${ }^{\mathbf{b}}$ (i)
}

\begin{abstract}
Özet: Büyüme ve hasılat modellerinin en önemli bileşenlerinden birisi ağaç hacim tahminleridir. Hacim tahminleri amaciyla kullanılan en modern yaklaşımlardan birisi de gövde çapı modelleridir. Günümüze kadar farklı formlarda pek çok gövde çapı modeli geliştirilmiştir. Gövde çapı modellerinin geliştirilmesi amacıyla geleneksel doğrusal olmayan en küçük kareler (ONLS) yöntemi başta olmak üzere farklı regresyon teknikleri kullanılmıştır. Son yıllarda, ormancılık uygulamalarında ve gövde çapı modellerinin geliştirilmesi amacıyla Kantil Regresyon (QR) tekniği de kullanılmaya başlamıştır. Bu çalışmada, doğal karaçam meşcereleri için ONLS ve QR teknikleriyle Max ve Burkhart (1976) modelini temel alan gövde çapı modeli geliştirilmiştir. Bu amaçla, birbirinden bağımsız iki farklı karaçam meşceresinden örnek ağaç verileri elde edilmiş ve verilerin bir kısmı (grup I) model geliştirmek, diğer kısmı ise (grup II) ise geliştirilen modelin test edilmesi amacıyla kullanılmıştır. Çalışmada, QR tekniği iki farklı kantil setini (3QR ve 5QR) esas alarak kullanılmıştır. Sonuçlar, dört farklı değerlendirme ölçütü kullanılarak tüm ağaç gövdesi ve on farklı nisbi boy sınıfı için karşılaştırılmıştır. QR tekniği ile elde edilen gövde çapı tahminlerinin hem tüm gövde hem de farklı nispi boy sınıfları için ONLS ile elde edilen sonuçlara göre daha başarılı olduğu görülmüştür. Çap tahminleri için 3QR ile elde edilen sonuçlar, 5QR ile elde edilen sonuçlara göre nispeten daha başarılıdır. Sonuç olarak, QR tekniği de, gövde çapı tahminleri için diğer regresyon tekniklerine alternatif olarak kullanılabilecek bir yaklaşımdır.
\end{abstract}

Anahtar kelimeler: Kantil regresyon, Kantil seti, Gövde çapı, Karaçam

\section{Development of stem diameter model using quantile regression}

\begin{abstract}
Tree volume estimates are one of the most important components of growth and yield models. Stem diameter models are one of the most modern approaches used for stem volume estimation. Different regression methods, especially the nonlinear least squares (ONLS) method, were used to develop stem diameter models. Recently, the quantile regression (QR) method has also been used in forestry applications for the development of taper models. In this study, a stem diameter model based on Max and Burkhart (1976) model was developed using ONLS and QR methods for natural black pine stands. For this purpose, sample tree data were obtained from two different black pine stands, and some of the data (group I) were used to develop the models and the rest of the data (group II) was used to test the models developed. In the study, the QR technique was used based on two different quantile sets $(3 \mathrm{QR}$ and $5 \mathrm{QR})$. The results were compared for the whole tree stem and ten different relative height classes using four different evaluation criteria. Evaluation statistics showed that both quantile regression models provided better results as compared to ONLS and $3 \mathrm{QR}$ model performed relatively better than $5 \mathrm{QR}$. In conclusion, QR technique is an approach that can be used as an alternative to other regression techniques for stem diameter estimations.
\end{abstract}

Keywords: Quantile regression, Quantile set, Stem diameter, Black pine

\section{Giriş}

Büyüme ve hasılat modellerinin en önemli altlıklarından birisi ağaç ve meşcere hacim tahminidir (Alkan vd., 2019). Bir meşceredeki ağaçların gövde hacmi ve biyokütlesinin tahmini, orman ekosisteminin yap1 ve fonksiyonlarının ekonomik ve ekolojik açıdan değerlendirilmesi için temel parametrelerdir (He vd., 2021). Hacim tahminleri, ağaç ve meşcerelere ilişkin hacmin ve bu hacim miktarının farklı ticari sınıflara dağılımının tahmininde (Dièguez-Aranda vd. 2006; Crecente-Campo vd., 2009), amenajman planlarının düzenlenmesinde (de-Miguel vd., 2012; Rodríguez vd. 2014), orman ürünleri sanayisinin geleceğine ilişkin projeksiyonların yapılmasında (Fang vd., 2000; Jiang vd., 2005; de-Miguel vd., 2012) ve uygun biyokütle dönüşüm faktörleri yardımı ile biyokütle ve karbon birikim miktarının tahmin edilmesinde (Castedo-Dorado vd., 2012; GòmezGarcia vd., 2015) kullanılmaktadır. Gövde çapı modelleri, günümüzde, dikili ağaçlara ilişkin hacimlerin doğru tahmini için var olan farklı yöntemler arasında en etkin ve çok yönlü yaklaşım tarzlarından biridir (Özçelik ve Alkan, 2011; Özçelik vd., 2018b) . Gövde çapı modellerinin ormancılık uygulamaları için diğer bir önemi de; büyüme ve hasılat modellerine entegre edilebilmesi, farklı yetişme ortamları ve farklı planlama alternatiflerinden elde edilecek ürün sınıflarının ve miktarlarının tahminine imkân sağlamasıdır (de-Miguel vd., 2012).

Sharma ve Parton (2009), bir ağaca ilişkin hacim tahmininin başarısının, gövde üzerindeki çap tahminlerinin başarısı ile doğru orantılı olduğunu ifade etmiştir. Ağaç gövdesinin farklı yüksekliklerindeki çap değerleri ne kadar doğru tahmin edilirse, gövdenin tamamı ya da herhangi bir
\ a Isparta Uygulamalı Bilimler Üniversitesi, Orman Fakültesi 32260, Isparta

b Isparta Uygulamalı Bilimler Üniversitesi, Lisansüstü Eğitim Enstitüsü, Orman Mühendisliği Anabilim Dalı 32260, Isparta

(a)
Citation (Atıf): Özçelik, R., Alkan, O., Kalkanlı, Ş., 2021. Kantil regresyon ile gövde çapı modelinin geliştirilmesi. Turkish Journal of Forestry, 22(3): 250-256. DOI: $\underline{10.18182 / \text { tjf.955881 }}$ 
bölümüne ilişkin hacim de o derece doğru tahmin edilebilecektir. Gövde çapı modellerinin geliştirilmesinde kullanılan iki temel değişken, göğüs çapı $(D)$ ve ağaç boyudur $(H)$. Ancak bazı çalışmalarda, model performansının arttırılması amacıyla çeşitli ağaç (tepe oranı ya da tepe taci yüksekliği) ya da meşcere özellikleri (meşcere sıklığı) de modele eş değişken olarak eklenmiştir. $\mathrm{Bu}$ çalışmalarda elde edilen sonuçlar farklılıklar göstermekle birlikte, modele yardımcı değişken eklenmesi ile modelin çap ve hacim tahmin performansının önemli derecede arttığ 1 gözlenmiştir. Ancak bu ekstra değişkenlerin ölçümünün zaman zaman zor ve masraflı olması nedeniyle, son yıllarda gövde çapı tahminleri amacıyla yeni metotların (regresyon teknikleri ve yapay sinir ağı modelleri vb.) kullanılmasına yönelik ilgi artmıştır.

Gövde çapı modellerinin geliştirilmesi amacıyla genellikle doğrusal olmayan en küçük kareler (ONLS) yöntemi kullanılmaktadır. Ancak, gövde çapı modellerinin geliştirilmesinde kullanılan çap değerleri, aynı ağaç üzerinde düzenli ya da düzensiz aralıklarla yapılan ölçümlerden elde edilmektedir. Bunun sonucu olarak da ölçüm değerleri birbiri ile ilişkili olmaktadır. Bu ilişki, regresyondaki kovaryans matrisinin yansız tahmini için gerekli olan hataların bağımsız olma kuralını ortadan kaldırmaktadır. Bu nedenle, son yıllardaki araştırmalar, hem yeni model formlarının (parçalı veya değişken şekil gövde çap1 modelleri vb.) geliştirilmesine hem de gövde formundaki ağaçlar arası değişkenliğin hesaplanmasına ilişkin yeni yaklaşımlara (metotlara) odaklanmıştır. Bu kapsamda, gövde çapı modellerinin geliştirilmesi amacıyla kullanılan yeni yaklaşım tarzlarından birisi de Kantil Regresyon (Quantile Regression-QR)'dur (Cao ve Wang, 2015). Bu teknik; mühendislik, finans, ekonomi ve tıp gibi birçok alanda yoğun bir şekilde kullanılmasına rağmen, ormancılık çalışmalarında sadece son 20 yıldır kullanılmaktadır. Kantil Regresyon (QR), bağımlı değişkenin dağılımındaki herhangi bir kantil ile bağımsız değişkenler arasındaki fonksiyonel ilişkinin tahmini amacıyla geliştirilmiştir (Koenker ve Bassett 1978). QR, özellikle koşullu kantillerin değişkenlik gösterdiği durumlarda daha kullanışlı bir yöntem olup, kantillere bağlı olarak regresyon katsayıları belirlenmektedir (Chen ve Wei, 2005). Bu yöntem ormancilıkta, orman envanterindeki hata değerlendirmelerinde (Mäkinen et al., 2008), doğal dal budanmasının sınırlarının belirlenmesinde (Zhang vd., 2005; Ducey ve Knapp, 2010), böcek yayılış (Evans ve Gregoire, 2007) ve hastalı (Evans ve Finkral, 2010) oranlarının belirlenmesinde, çap yüzdelerinin belirlenmesinde (Mehtätalo vd., 2008), çap gelişimimi çalışmasında (Bohora ve Cao, 2014), büyüme ve hasılat modellerinin geliştirilmesinde (Farias vd., 2021; Paula vd., 2021), gövde çapı modelinin geliştirilmesinde (Cao ve Wang, 2015; Ma ve Jiang, 2019; Özçelik vd., 2019; He vd., 2021) ve çap-boy modellerinin geliştirilmesinde (Rust, 2014; Zang vd., 2016; Özçelik vd., 2018a) kullanılmıştır.

QR yaklaşımını temel alan ilk gövde çapı modeli Cao ve Wang (2015) tarafindan geliştirilmiştir. Çalışmada, Max ve Burkhart (1976) tarafından geliştirilen gövde çapı modelinin değiştirilmiş bir formu kullanılarak iki farklı kantil seti (5 kantil-5QR ve 3 kantil-3QR) yardımıyla çap tahminleri yapılmış. Çalışma sonucunda 3 ve 5 kantil setleri arasında önemli fark olmadığı, 5 kantili temel alan QR'nin çap tahminlerinde daha başarılı olduğu görülmüştür. Ma ve Jiang (2019) tarafında yapılan çalışmada, huş ağaçları için
Max ve Burkhart (1976) tarafından geliştirilen gövde çapı modeli kullanılarak doğrusal olmayan kantil regresyon tekniği ile gövde çapı modelleri geliştirilmiştir. Çalışmada farkl1 kantiller $(\tau=0.1,0.2,0.3,0.4,0.5,0.6,0.7,0.8$ ve $0.9)$ ve kantil setleri $(3,5,7$ ve 9 kantil) kullanılarak elde edilen sonuçlar karşılaştırılmıştır. En başarılı çap tahminlerinin 5 kantil seti ile elde edildiği görülmüştür. He vd. (2021) tarafından yapılan çalışmada, huş ağaçlarının gövde çapı tahmini amaciyla Kozak (2004) tarafindan geliştirilen gövde çapı modelini temel alan dört farklı regresyon tekniği (en küçük kareler yöntemi (ONLS), sabitetkili model (FE), kantil regresyon (QR) ve genelleştirilmiş eklemeli model (GAM)) karşılaştırılmıştır. Gövde çapı tahminleri açısından GAM en başarılı sonuçları üretirken, QR üçüncü sırada yer almıştır. Ülkemizde ise, QR metodu ormancılık alanında ilk kez çap-boy modeli geliştirmek amacıyla kullanılmıștır (Özçelik vd., 2018a). Özçelik vd. (2019) tarafından yapılan çalışmada ise, Sharma ve Parton (2009) tarafından geliştirilen gövde çapı modelini temel alan dört farklı regresyon tekniği (sabit etkili (FE), karışık etkili (ME), kantil regresyon (üç kantil (3QR) ve 5 kantil (5QR)) ve yapay sinir ağı yöntemi karşılaştırılmıştır. Çalışmada $\mathrm{ME}, 3 \mathrm{QR}$ ve $5 \mathrm{QR}$ yöntemlerinin FE’ye göre daha başarılı sonuçlar ürettiği görülmüştür. $3 \mathrm{QR}$ ve $5 \mathrm{QR}$ yöntemleri arasında büyük bir farkın olmadığı ancak, $5 \mathrm{QR}$ yönteminin nispeten daha başarılı olduğu ifade edilmiştir.

Karaçam ülkemizin ekolojik ve ekonomik açıdan en önemli asli ağaç türlerinden birisidir. 2019 yılı orman envanteri verilerine göre karaçam ormanları yaklaşı 4.4 milyon hektar ile ülke ormanlık alanlarının yaklaşık \%19'unu kaplamaktadır (OGM, 2019). Karaçam ormanları ekonomik önemi yanında biyolojik çeşitliliğin korunması ve küresel iklim değişiminin olumsuz etkilerinin azaltılması açısından da önemli çevresel işlevlere sahiptir. Bu nedenle, karaçam ormanlarının sürdürülebilir yönetimi ve çok amaçlı kullanımı için güvenilir büyüme ve hasılat modellerine ihtiyaç duyulmaktadır. Bu çalışmada, gövde çapı modellerinin geliştirilmesinde ve çap tahminlerinde geleneksel doğrusal olmayan en küçük kareler yöntemi (ONLS) ile Kantil regresyon tekniğinin başarı durumları karşılaştırmalı olarak değerlendirilmiştir. Çalışmada, her iki regresyon tekniğine de temel olması amaciyla, pek çok çalışmada başarı ile kullanılan Max ve Burkhart (1976) tarafından geliştirilen parçalı gövde çapı modeli seçilmiştir. QR yaklaşımı, 3 kantil (3QR) ve 5 kantil (5QR) olmak üzere iki farklı kantil seti ile değerlendirilmiştir.

\section{Materyal ve yöntem}

\subsection{Materyal}

Örnek ağaç verileri, Isparta Orman Bölge Müdürlüğünün iki farklı alanındaki doğal ve saf karaçam meşcerelerinden toplanmıştır. Verilerin Grup I olarak ifade edilen kısmı (172 örnek ağaç), Eğirdir Orman İşletme Müdürlüğünden, Grup II olarak ifade edilen diğer kısmı ise Sütçüler Orman İşletme Müdürlüğü (240 örnek ağaç) doğal ve saf karaçam meşcerelerinden toplanmıştır. Örnek ağaçlar, çalışma alanları içerisinde mevcut tüm çap ve boy sınıflarını ile yetişme ortamı şartlarını temsil edecek şekilde galip ya da müşterek galip ağaçlar arasından seçilmiştir. Örnek ağaçlar seçilirken gövdeleri çatallı, tepeleri kırık, azman yapmış ve gövde formu bozuk bireyler olmamasına azami özen gösterilmiştir. Çalışma kapsamında toplam 412 adet 
örnek ağaç üzerinde detaylı ölçümler yapılmıştır. Bu amaçla, örnek ağaçlar kesilmeden önce kabuklu göğüs çapları $(D, \mathrm{~cm})$, kesildikten sonra, bütün ağaçların şerit metre yardımı ile toplam boyu $(H, m)$ ve dijital çap ölçer yardımı ile 1.3 m'den sonra yaklaşık olarak $1 \mathrm{~m}$ aralıkla ağaçların en uç noktasına kadar değişik yükseklikteki $(h)$ çap $(d)$ değerleri ölçülmüştür. Grup I'de yer alan 172 ağaç gövde çapı modelinin geliştirilmesi amacıyla, Grup II'de yer alan 240 ağaç ise geliştirilen modellerin test edilmesi amacıyla kullanılmıştır. Her iki grupta yer alan örnek ağaçlara ilişkin nisbi boy-nispi çap dağılım grafikleri Şekil 1a ve b'de; nitelendirici istatistikler ise Çizelge 1'de verilmiştir.

\subsection{Yöntem}

\section{Gövde çapı modeli}

Yüz yılı aşkındır pek çok ağaç türü için değişik formlarda gövde çapı modelleri geliştirilmiştir (Max ve Burkhart, 1976; Cao vd., 1980; Biging, 1984; Clark vd., 1991; Fang vd., 2000; Kozak, 2004; Sharma ve Zhang, 2004; Sharma ve Parton, 2009). Bazı araştırmacılar, parçalı gövde çapı modellerinin, diğer gövde çapı modellerine göre daha üstün olduklarını ifade etmiştir (Martin, 1981; Clark vd., 1991; Figueiredo-Filho vd., 1996; Jiang, 2004; Dieguez-Aranda vd., 2006; Coble ve Hilpp, 2006; Özçelik ve Crecente-Campo, 2016). Parçalı gövde çapı modellerinin diğer gövde çapı modellerine göre en önemli üstünlüklerinden birisi, gövde çap1 modellerinin hacim hesaplamaları için kolaylıkla hacim denklemlerine dönüştürülebiliyor olmasıdır (Fang vd., 2000). Bu nedenle, bu çalışmada geleneksel regresyon yöntemine (ONLS) ve Kantil regresyon (QR) yöntemine altlık olması amaciyla Max ve Burkhart (1976) tarafından geliştirilen parçalı gövde çapı modeli seçilmiştir. Max ve Burkhart (1976) parçalı gövde çapı modeli, üç farklı ikinci dereceden fonksiyondan oluşmakta ve bu fonksiyonlar iki katılım noktası ile birleştirilmektedir. $\mathrm{Bu}$ nedenle de, karmaşık ağaç gövde formunun tanımlanması için yeterince esneklik sağlamaktadır (Cao ve Wang, 2015). Bu modelin genel formu aşağıdaki gibi yazılabilmektedir:

$\hat{y}\left(x_{i j}\right)=D\left[b_{1}\left(x_{i j}-1\right)+b_{2}\left(x_{i j}^{2}-1\right)+b_{3}\left(a_{1}-x_{i j}\right)^{2} I_{1}+\right.$ $\left.b_{4}\left(a_{2}-x_{i j}\right)^{2} I_{2}\right]^{0.5}$
Burada:

$\hat{y}\left(x_{i j}\right)=$ verilen bir $x_{i j \mathrm{ji}}$ değeri için $\hat{y}$ nin tahmin edilen değerini,

$y_{i j}=y\left(x_{i j}\right)=d_{i j}^{2} / D_{i}^{2}$

$D_{i}=i$.ăgacın göğüs çapını $(i=1,2,3, \ldots, N)$

$N=$ örnekteki ağaç sayısını

$d_{i j}=i . a \breve{g} a c ̧$ üzerindeki $h_{i j}$ yüksekliğinde ölçülen $j$.

kabuklu göğüs çapını

$n_{i}=i . a \breve{g} a c ̧ i c ̧ i n$ çap ölçümlerinin sayısını

$x_{i j}=h_{i j} / H_{i}$

$H_{i}=i . a$ ğacın boyunu $(m)$

$a_{1}$ ve $a_{2}=$ tahmin edilen katılma noktaların

$I_{i}=1$ e ğer $x_{i j} \leq a_{i}$ ve $I_{i}=0$ e $\breve{g}$ er $x_{i j} \geq a_{i}$

$b_{i}=$ regresyon katsayılarını ifade etmektedir.

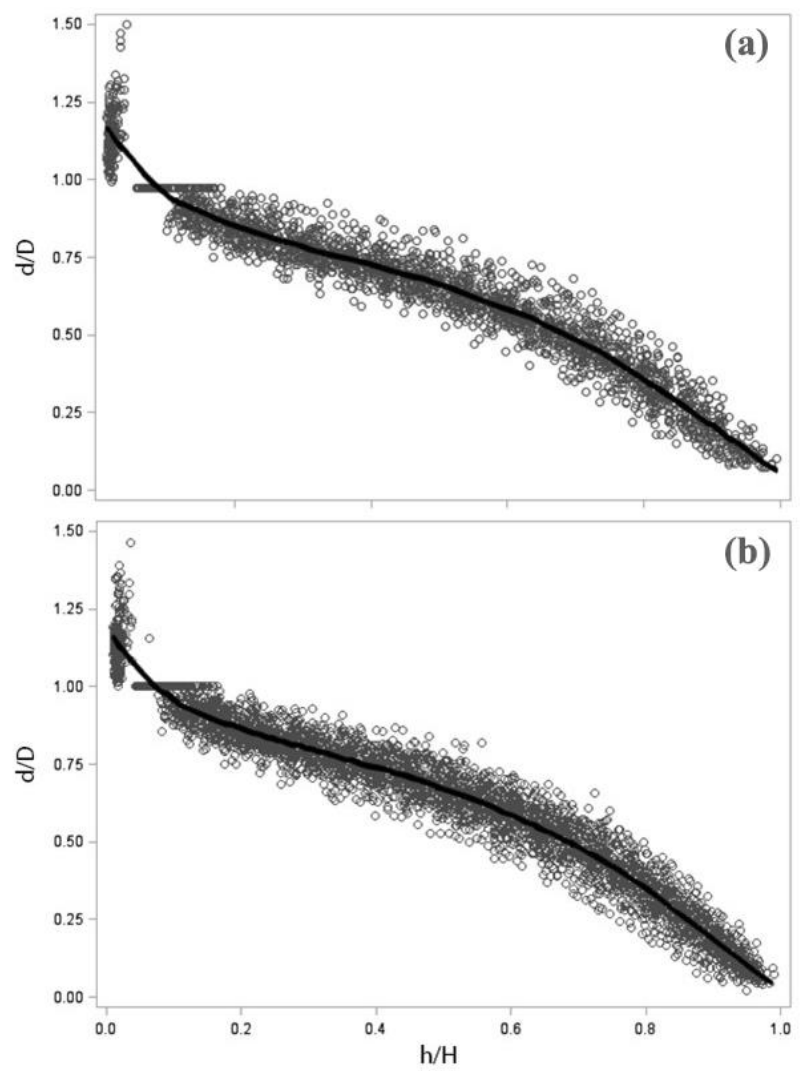

Şekil 1. Model geliştirmek (a) ve test etmek (b) amacıyla kullanılan örnek ağaçlara ilişkin nispi boy-nispi çap dağılım grafikleri

Çizelge 1. Model geliştirmek ve test etmek için kullanılan örnek ağaçlara ilişkin nitelendirici istatistikler

\begin{tabular}{|c|c|c|c|c|}
\hline Veri & Ortalama & $\mathrm{SD}^{\mathrm{a}}$ & Minimum & Maksimum \\
\hline \multicolumn{5}{|c|}{ Model Geliştirme Verisi (n = 172 ağaç ve 2433 çap ölçümü) } \\
\hline Göğüs çap1, $D(\mathrm{~cm})$ & 31.4 & 10.21 & 9.0 & 56.6 \\
\hline Ağaç Boyu, $H(\mathrm{~m})$ & 15.57 & 3.22 & 7.2 & 22.6 \\
\hline Disk çapı, dob $(\mathrm{cm})$ & 21.2 & 11.0 & 2.0 & 62.7 \\
\hline Disk yüksekliği, $h(\mathrm{~m})$ & 7.27 & 4.67 & 0.3 & 20.3 \\
\hline Hacim, $V\left(\mathrm{~m}^{3}\right)$ & 0.67 & 0.51 & 0.02 & 2.21 \\
\hline \multicolumn{5}{|c|}{ Model Test Verisi ( $\mathrm{n}=240$ ağaç ve 4230 çap ölçümü) } \\
\hline Göğüs çap1, $D(\mathrm{~cm})$ & 33.2 & 9.96 & 10.5 & 59.0 \\
\hline Ağaç Boyu, $H(\mathrm{~m})$ & 19.30 & 4.35 & 7.90 & 3.30 \\
\hline Disk çap1, $d o b(\mathrm{~cm})$ & 21.5 & 11.17 & 1.0 & 6.3 \\
\hline Disk yüksekliği, $h(\mathrm{~m}$ & 9.18 & 5.96 & 0.30 & 29.3 \\
\hline Hacim, $V\left(\mathrm{~m}^{3}\right)$ & 0.89 & 0.68 & 0.03 & 3.37 \\
\hline
\end{tabular}




\section{Kantil regresyon}

Doğrusal olmayan en küçük kareler $(O N L S)$ yöntemi için hataların bağımsız olması, verilerin normal dağılıma sahip olması ve bağımsız değişkenler arasında çoklu bağıntı probleminin olmaması gibi bazı temel varsayımların sağlanması gerekmektedir. Bu varsayımların sağlanamadığı ya da veri yapısında ekstrem değerlerin bulunduğu durumlarda $O N L S$ yönteminin etkinliği oldukça azalmakta ve parametre tahminlerinin varyansinda tutarsızlıklar ortaya çıkmaktadır (West, 1984; Yang vd., 2009; Huang vd., 2017). Günümüzde, birç̧ok veri seti normal dağılım göstermemekte ve veri yapısı içerisinde diğer gözlemlerden önemli derecede farklılık gösteren aykırı değerler barındırabilmektedir. $\mathrm{Bu}$ gibi durumlara özellikle son yıllarda alternatif teknikler olarak karışık-etkili modelleme ve kantil (QR) regresyon kullanılmaya başlamıştır (Bohora ve Cao, 2014; Cao ve Wang, 2015; Zang vd., 2016; Özçelik vd., 2018; Özçelik vd., 2019). Diğer yandan son yıllarda hiyerarşik yap1 gösteren verilerin analizinde de QR kullanılmaktadır (Koenker, 2004).

Çalışma kapsamında, Kantil regresyon ile gövde çapı modelinin geliştirilmesinde aşağıda açıklanan yöntem izlenmiştir. Kantil regresyon ile gövde çap1 modelinin geliştirilmesine ilişskin ayrıntılı bilgiler; Cao ve Wang (2015) ve Özçelik vd. (2019)'da bulunabilir.

$\tau$. gövde çapı kantilini tahmin etmek için denklem (1) deki aynı model formu denklem (2)'deki şekliyle düzenlenerek kullanılmıştır.

$\hat{y}_{\tau}\left(x_{i j}\right)=\beta_{1 \tau}\left(x_{i j}-1\right)+\beta_{2 \tau}\left(x_{i j}^{2}-1\right)+\beta_{3 \tau}\left(\alpha_{1 \tau}-\right.$ $\left.x_{i j}\right)^{2} I_{1}+\beta_{4 \tau}\left(\alpha_{2 \tau}-x_{i j}\right)^{2} I_{2}$

Burada, $\hat{y}_{\tau}\left(x_{i j}\right)$, verilen $x_{i j}$ için $y$ 'nin $\tau$. kantilinin tahmin edilen değeridir. En küçük kareler yönteminin aksine, kantil regresyon denklem (3)'ün minimizasyonu ile parametreleri tahmin etmektedir (Cao ve Wang, 2015).

$S=\sum_{y\left(x_{i j)} \in A\right.} \tau\left[y\left(x_{i j}\right)-\hat{y}_{\tau}\left(x_{i j}\right)\right]+\sum_{y\left(x_{i j)} \notin A\right.}(1-$

$\tau)\left[y\left(x_{i j}\right)-\hat{y}_{\tau}\left(x_{i j}\right)\right]$

Burada, $x_{i j} \leq 1$ olduğu zaman $y\left(x_{i j}\right) \geq \hat{y}_{\tau}\left(x_{i j}\right)$ ve $x_{i j}>1$ olduğu zaman $y\left(x_{i j}\right)<\hat{y}_{\tau}\left(x_{i j}\right)^{\prime}$ 'dir. $\quad x_{i j} \leq 1$ olduğunda, daha düşük kantil için eğri daha yüksek kantilinkinden aşağıda yer alır ve $x_{i j}>1$ için bunun tersi doğrudur çünkü, her iki eğride $x_{i j}=1$ noktasından geçmektedir. Çalışmada, SAS alt sekmesi NLP kullanılarak
$0.1,0.3,0.5,0.7$ ve 0.9 kantillerini temel alan kantil regresyon seti geliştirilmiştir.

\section{Değerlendirme}

Çalışmada geleneksel regresyon yöntemi (ONLS) ile 3 kantili temel alan $(0.1,0.5$, and 0.9$) 3 \mathrm{QR}$ yöntemi ve beş kantili temel alan $(0.1,0.3,0.5,0.7$, and 0.9) 5QR yöntemleri değerlendirilmiştir. Kozak ve Kozak (2003), modelin geçerliliğinin test edilmesi için model performanslarının değerlendirilmesi gerektiğini ve bu amaçla genellikle bağımsız veri setlerinden yararlanıldığını ifade etmiştir. Bağımsız veri setinin olmadığı durumlarda, çapraz geçerlilik testi veya veri gruplandırma gibi alternatif yöntemlerin kullanılabileceğini ifade etmiştir. Ancak, bu yöntemlerin kullanılması ile elde edilecek değerlendirme sonuçlarının, tüm veri setinin analizi ile elde edilen değerlendirme istatistikleri ile karşılaştırıldığında nadiren ekstra katk1 sağlayan bilgiler ortaya koyduğunu ifade etmiştir. $\mathrm{Bu}$ nedenle çalışma kapsamında model performanslarının değerlendirilmesi amaciyla model geliştirme verisinden bağımsız olarak farklı bir yöreden sağlanan veri seti kullanılmıştır.

$\mathrm{Bu}$ amaçla hem model geliştirme verileri hem de model test verileri için aşağıdaki dört değerlendirme istatistiği hesaplanmıştır.

Ortalama Hata: $M D=\frac{\sum_{i=1}^{n} \sum_{j=1}^{n_{i}}\left(d_{i j}-\hat{d}_{i j}\right)}{\sum_{i=1}^{n} n_{i}}$

Ortalama Mutlak Hata: $M A D=\frac{\sum_{i=1}^{n} \sum_{j=1}^{n_{i}}\left|d_{i j}-\hat{d}_{i j}\right|}{\sum_{i=1}^{n} n_{i}}$

Hata Kareler Ortalamasının Karekökü: $R M S E=$ $\left[\sum_{i=1}^{n} \sum_{j=1}^{n_{i}}\left(d_{i j}-\hat{d}_{i j}\right)^{2}\right] / \sum_{i=1}^{n} n_{i}$

Belirtme Katsayısı: $R^{2}=1-\frac{\sum_{i=1}^{n} \Sigma_{j=1}^{n_{i}}\left(d_{i j}-\hat{d}_{i j}\right)^{2}}{\sum_{i=1}^{n} \sum_{j=1}^{n_{i}}\left(d_{i j}-\bar{d}_{i}\right)^{2}}$

Burada, $n$ ağaç sayısını, $n_{i} i$. ağaç gövdesi üzerindeki çap ölçümlerinin sayısını, $d_{i j}$ ve $\hat{d}_{i j}$ sırasıyla $i$ th ağaç üzerindeki $j$. gövde çapı için ölçülen ve tahmin edilen değerleri ve $\bar{d}_{i}$ ise $d_{i j}$ 'nin ortalamasını ifade etmektedir.

\section{Bulgular ve tartışma}

Model geliștirme verileri kullanılarak ONLS ve QR teknikleri ile elde edilen parametre tahminleri Çizelge 2'de verilmiştir. Her iki regresyon tekniği ile elde edilen parametre tahminleri 0.0001 düzeyinde anlamlı bulunmuştur.

Çizelge 2. ONLS ve QR teknikleri için parametre tahminleri

\begin{tabular}{|c|c|c|c|c|c|c|}
\hline \multirow{2}{*}{ Parametreler } & \multirow{2}{*}{ ONLS } & \multicolumn{5}{|c|}{ QR } \\
\hline & & $\tau=0.1$ & $\tau=0.3$ & $\tau=0.5$ & $\tau=0.7$ & $\tau=0.9$ \\
\hline$\beta_{1}$ & -6.10083 & -4.96859 & -5.17964 & -5.92421 & -4.43472 & -6.34665 \\
\hline$\beta_{2}$ & 2.98986 & 2.52283 & 2.56395 & 2.90192 & 2.00776 & 2.89049 \\
\hline$\beta_{3}$ & -3.26929 & -2.46440 & -2.62042 & -2.97507 & -2.05307 & -3.19864 \\
\hline$\beta_{4}$ & 16.18681 & 15.52829 & 15.82862 & 16.62237 & 18.49029 & 16.83915 \\
\hline$\alpha_{1}$ & 0.82375 & 0.79893 & 0.80737 & 0.83510 & 0.83151 & 0.87064 \\
\hline$\alpha_{2}$ & 0.18324 & 0.16329 & 0.17694 & 0.17925 & 0.17550 & 0.21037 \\
\hline
\end{tabular}


Şekil 2'de ise 5QR ile elde edilen regresyon eğrilerinin bağımsız veri seti ile birlikte gösterimi verilmiştir.

Model geliştirme verileri için ONLS, 3QR ve 5QR teknikleri için hesaplanan değerlendirme istatistikleri ise Çizelge 3'te verilmiştir. Çizelge 3'teki sonuçlar değerlendirildiğinde; kullanılan üç değerlendirme ölçütü için de en başarılı sonuçların 3QR ile; en başarısız sonuçların ise ONLS ile elde edildiği görülmektedir. Farklı kantil setlerini esas alan $3 \mathrm{QR}$ ve $5 \mathrm{QR}$ tekniklerinin başarı performansları arasında önemli sayılabilecek farklılıkların bulunmadığı da görülmüştür.

Bağımsız veri seti için iki farklı regresyon tekniği ile elde edilen sonuçlar ise Çizelge 4'te verilmiştir. Burada da model geliştirme verilerine benzer bir sonuç ortaya çıkmıştır. En başarılı sonuçlar 3QR ile; en başarısız sonuçlar ise ONLS ile elde edilmiştir. Çizelge 4'ten de görüleceği gibi bağımsız veri seti için $3 \mathrm{QR}$ ve $5 \mathrm{QR}$ ile elde edilen sonuçlar arasında önemli bir fark bulunmamaktadır. Diğer önemli bir durum da, 3QR ve 5QR ile model geliştirme ve model test verileri için birbirine yakın sonuçlar ortaya çıkmış iken, ONLS ile model geliştirme ve model test verileri için elde edilen sonuçlar arasında ölçüt değerleri açısından nispeten önemli farklılıklar bulunmuştur.

Ma ve Jiang (2019) tarafindan Max ve Burkhart (1976) tarafından geliştirilen gövde çapı modeli temel alınarak yapılan çap tahminlerinde bu çalışmanın aksine, en başarılı kantil setinin 5QR olduğu ortaya konmuştur. Yine Özçelik vd. (2019) tarafindan yapılan çalışmada da, farklı kalibrasyon alternatifleri için en başarılı gövde çapı tahminleri $5 \mathrm{QR}$ ile elde edilmiştir. Ancak $3 \mathrm{QR}$ ve $5 \mathrm{QR}$ ile elde edilen sonuçlar arasında önemli bir farklılık olmadığ 1 da ifade edilmiştir. Benzer sonuçlar Cao ve Wang (2015) tarafında da rapor edilmiştir. Kalibre edilmiş 5QR ile elde edilen sonuçlar çap tahminleri açısından az da olsa kalibre edilmiş $3 Q R$ ye göre daha başarılıdır. Burada belirtmek gerekir ki, yukarıdaki çalışmalarda farklı kantil setlerini kullanan kantil regresyon tekniği için kalibrasyon işlemi yapılmış iken, bu çalışmada modellerin kalibrasyonu yapılmamıştır. Xin ve Jiang (2020) tarafindan yapılan çalışmada ise, farklı formlarda gövde çapı modelleri (Kozak vd., 1969; Max ve Burkhart, 1976; Kozak 2004); QR ve ONLS teknikleri kullanılarak geliştirilmiş ve 4 farklı ölçüt değeri kullanılarak karşılaştırılmıştır. Her bir gövde çapı modeli ayrı ayrı değerlendirildiğinde; QR tekniği kullanılarak geliştirilen modellerin, ONLS yaklaşımı ile geliştirilen modellere göre daha başarılı sonuçlar ürettiği görülmüştür. Genel olarak değerlendirildiğinde ise, Kantil regresyonu temel alan Kozak (2004) modelinin diğer modellere göre daha başarılı ölçüt değerleri ürettiği ortaya konmuştur.

Max ve Burkhart (1976) tarafından geliştirilen gövde çapı modelini temel alan her iki regresyon tekniği ile elde edilen sonuçların ağaç gövdesi boyunca farklı noktalarda göstermiş olduğu performanslarını değerlendirebilmek için, regresyon tekniklerinin performansı nisbi boy $\left(\frac{h}{H}\right)$ sinıfları içinde değerlendirilmiştir. Bu amaçla bağımsız veri seti on nisbi boy sınıfına ayrılmış ve her nispi boy sınıfı için farklı regresyon teknikleri ile elde edilen MAD, RMSE ve $\mathrm{R}^{2}$ değerleri hesaplanmıştır. $\mathrm{Bu}$ değerlendirmeye ilişkin sonuçlar da Çizelge 5'te verilmiştir. Çizelge 5'ten de görüleceği gibi, $3 \mathrm{QR}$ ve $5 \mathrm{QR}$ teknikleri ile elde edilen sonuçların ONLS ile elde edilen sonuçlara göre nispi boy sınıfları için daha başarılı olduğu görülmektedir. Sadece ağacın dip kısmında (\%0-\%10) ONLS daha başarılıdır. 3QR ile elde edilen sonuçların toplam ağaç boyunun \%40-60'lık bölümü hariç, 5QR ile elde edilen sonuçlara göre daha başarılı olduğu da görülmektedir. Özellikle gövdenin \%20\%70'lik bölümünde $3 \mathrm{QR}$ ve 5QR ile elde edilen sonuçların ağaç gövdesinin diğer bölümlerine göre daha tutarlı ve başarılı olduğu da görülmektedir.

Şekil 3'te ise bağımsız veri seti için ONLS, 3QR ve $5 \mathrm{QR}$ ile elde edilen çap tahminleri ile ortaya çıan hata dağılım grafiği verilmiştir. $3 \mathrm{QR}$ ve $5 \mathrm{QR}$ ile ONLS'ye göre daha homojen bir hata dağılımının ortaya çıktığı görülmektedir. Her iki regresyon tekniğinin de kalın çap değerleri için daha yüksek hata dağılım varyansına sahip olduğu görülmektedir. Bu durumun bu çap sinıflarındaki ağaç sayısının nispeten diğer çap sınıflarına göre az olması ile de ilişkisi olduğu söylenebilir. Özellikle, $50 \mathrm{~cm}$ 'den daha kalın çap değerinin nispeten az olduğu görülmektedir. Bu durum modelin tahmin performansı üzerinde olumsuz etki göstermiştir.

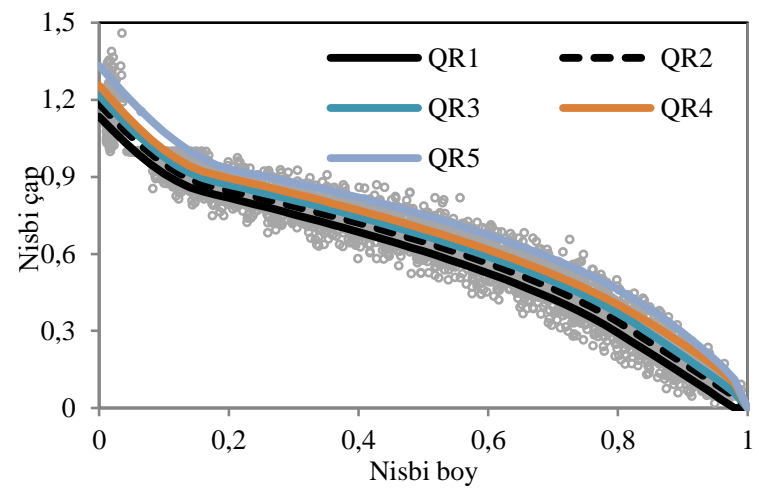

Şekil 2. Bağımsız veri setindeki ölçülen çap-boy değerleri ile kantil regresyon eğrilerinin $(0.1,0.3,0.5,0.7$, ve 0.9$)$ gösterimi

Çizelge 3. Model geliştirme verileri için farklı regresyon teknikleri ile elde edilen değerlendirme istatistikleri

\begin{tabular}{ccccc}
\hline Models & $n$ & $M D$ & $M A D$ & $R^{2}$ \\
\hline $3 Q R$ & 2424 & $\underline{0.0015}$ & $\underline{1.0239}$ & $\underline{0.9831}$ \\
$5 Q R$ & 2424 & 0.0076 & 1.0387 & 0.9827 \\
ONLS & 2424 & 0.0123 & 1.3892 & 0.9708 \\
\hline
\end{tabular}

Çizelge 4. Bağımsız veri seti için farklı regresyon teknikleri ile elde edilen değerlendirme istatistikleri

\begin{tabular}{ccccc}
\hline Models & $n$ & $M D$ & $M A D$ & $R^{2}$ \\
\hline $3 Q R$ & 4230 & $\underline{0.0248}$ & $\underline{1.0247}$ & $\underline{0.9846}$ \\
$5 Q R$ & 4230 & 0.0311 & 1.0343 & 0.9843 \\
ONLS & 4230 & 0.6562 & 1.4845 & 0.9688 \\
\hline
\end{tabular}


Çizelge 5. Bağımsız veri seti kullanılarak nisbi boy sınıfları (h/H) için elde edilen değerlendirme istatistikleri

\begin{tabular}{|c|c|c|c|c|}
\hline \multirow{2}{*}{ Nisbi boy sınıfları } & \multirow{2}{*}{$n$} & ONLS & $3 \mathrm{QR}$ & $5 \mathrm{QR}$ \\
\hline & & \multicolumn{3}{|c|}{ MAD } \\
\hline $0.0 \leq \mathrm{h} / \mathrm{H}<0.1$ & 484 & 1.6386 & 1.7367 & 1.7534 \\
\hline $0.1 \leq \mathrm{h} / \mathrm{H}<0.2$ & 431 & $\overline{1.2263}$ & $\underline{1.0384}$ & 1.0429 \\
\hline $0.2 \leq \mathrm{h} / \mathrm{H}<0.3$ & 442 & 1.1821 & $\overline{0.8383}$ & 0.8451 \\
\hline $0.3 \leq \mathrm{h} / \mathrm{H}<0.4$ & 432 & 1.3379 & 0.7957 & 0.7984 \\
\hline $0.4 \leq \mathrm{h} / \mathrm{H}<0.5$ & 429 & 1.4383 & $\overline{0.8549}$ & $\underline{0.8501}$ \\
\hline $0.5 \leq \mathrm{h} / \mathrm{H}<0.6$ & 448 & 1.5020 & 0.9049 & 0.8937 \\
\hline $0.6 \leq \mathrm{h} / \mathrm{H}<0.7$ & 434 & 1.6085 & $\underline{0.8868}$ & $\overline{0.8882}$ \\
\hline $0.7 \leq \mathrm{h} / \mathrm{H}<0.8$ & 437 & 1.7946 & 1.0226 & 1.0396 \\
\hline $0.8 \leq \mathrm{h} / \mathrm{H}<0.9$ & 426 & 1.7342 & $\overline{1.1104}$ & 1.1171 \\
\hline $0.9 \leq \mathrm{h} / \mathrm{H} \leq 1.0$ & 267 & 1.2965 & 0.9168 & 1.0006 \\
\hline \multirow[t]{2}{*}{ Tüm veri } & 4230 & 1.4845 & 1.0247 & 1.0343 \\
\hline & & \multicolumn{3}{|c|}{$\overline{\mathrm{RMSE}}$} \\
\hline $0.0 \leq \mathrm{h} / \mathrm{H}<0.1$ & 484 & 2.1877 & 2.2304 & 2.2506 \\
\hline $0.1 \leq \mathrm{h} / \mathrm{H}<0.2$ & 431 & $\overline{1.5583}$ & $\underline{1.3412}$ & 1.3443 \\
\hline $0.2 \leq \mathrm{h} / \mathrm{H}<0.3$ & 442 & 1.5227 & $\underline{1.0758}$ & 1.0862 \\
\hline $0.3 \leq \mathrm{h} / \mathrm{H}<0.4$ & 432 & 1.7538 & $\overline{1.0442}$ & 1.0481 \\
\hline $0.4 \leq \mathrm{h} / \mathrm{H}<0.5$ & 429 & 1.9050 & $\overline{1.1812}$ & $\underline{1.1734}$ \\
\hline $0.5 \leq \mathrm{h} / \mathrm{H}<0.6$ & 448 & 1.9992 & 1.2508 & $\overline{1.2361}$ \\
\hline $0.6 \leq \mathrm{h} / \mathrm{H}<0.7$ & 434 & 2.1469 & $\underline{1.1769}$ & $\overline{1.1783}$ \\
\hline $0.7 \leq \mathrm{h} / \mathrm{H}<0.8$ & 437 & 2.3952 & $\underline{1.3517}$ & 1.3681 \\
\hline $0.8 \leq \mathrm{h} / \mathrm{H}<0.9$ & 426 & 2.3419 & $\underline{1.5131}$ & 1.5133 \\
\hline $0.9 \leq \mathrm{h} / \mathrm{H} \leq 1.0$ & 267 & 1.7307 & 1.2530 & 1.3665 \\
\hline \multirow[t]{2}{*}{ Tüm veri } & 4230 & 1.9748 & 1.3418 & 1.3565 \\
\hline & & \multicolumn{3}{|c|}{$\mathrm{R}^{2}$} \\
\hline $0.0 \leq \mathrm{h} / \mathrm{H}<0.1$ & 484 & $\underline{0.9547}$ & 0.9530 & 0.9521 \\
\hline $0.1 \leq \mathrm{h} / \mathrm{H}<0.2$ & 431 & $\overline{0.9672}$ & $\underline{0.9757}$ & 0.9756 \\
\hline $0.2 \leq \mathrm{h} / \mathrm{H}<0.3$ & 442 & 0.9661 & $\overline{0.9831}$ & 0.9828 \\
\hline $0.3 \leq \mathrm{h} / \mathrm{H}<0.4$ & 432 & 0.9498 & $\underline{0.9822}$ & 0.9821 \\
\hline $0.4 \leq \mathrm{h} / \mathrm{H}<0.5$ & 429 & 0.9320 & $\overline{0.9739}$ & $\underline{0.9742}$ \\
\hline $0.5 \leq \mathrm{h} / \mathrm{H}<0.6$ & 448 & 0.9122 & 0.9656 & $\overline{0.9664}$ \\
\hline $0.6 \leq \mathrm{h} / \mathrm{H}<0.7$ & 434 & 0.8640 & $\underline{0.9591}$ & $\overline{0.9590}$ \\
\hline $0.7 \leq \mathrm{h} / \mathrm{H}<0.8$ & 437 & 0.7389 & $\underline{0.9168}$ & 0.9148 \\
\hline $0.8 \leq \mathrm{h} / \mathrm{H}<0.9$ & 426 & 0.5456 & 0.8103 & $\underline{0.8103}$ \\
\hline $0.9 \leq \mathrm{h} / \mathrm{H} \leq 1.0$ & 267 & 0.1473 & 0.5528 & $\overline{0.4681}$ \\
\hline Tüm veri & 4230 & 0.9688 & 0.9846 & 0.9843 \\
\hline
\end{tabular}

\section{Sonuç}

Bu çalışmada, gövde çapı tahmini amacıyla, doğal ve saf karaçam meşcerelerinden elde edilen veriler kullanılarak iki farklı regresyon tekniğini temel alan (ONLS ve QR) gövde çap1 modeli geliştirilmiştir. Her iki regresyon tekniğine temel olmak üzere Max ve Burkhart (1976) tarafindan geliştirilen parçalı gövde çapı modeli seçilmiş ve kullanılmıştır. Kantil regresyon tekniği için $3(0.1,0.5$ ve $0.9)$ ve $5(0.1,0.3,0.5,0.7$ ve 0.9$)$ kantil setlerini esas alan iki farklı yöntem kullanılmıştır. Her iki regresyon tekniği ile de elde edilen sonuçlar iki farklı veri grubu (model geliştirme ve model test verileri) için ayrı ayrı değerlendirilmiştir. Elde edilen sonuçlar, kantil regresyon tekniği ile ONLS'ye göre hem toplamda hem de farklı nispi boy sınıfları için daha başarılı çap tahminleri yapılabildiğini göstermiştir. $3 \mathrm{QR}$ ve $5 \mathrm{QR}$ için elde edilen sonuçlar karşılaştırıldığında ise, 3QR ile elde edilen sonuçların 5 QR'ye göre nispeten daha başarılı olduğunu ortaya koymuştur. Sonuç olarak, gövde çapı tahminleri amaciyla kantil regresyon tekniğinin kullanımı, ülkemizde diğer regresyon tekniklerine alternatif bir yaklaşım olarak önerilebilir.
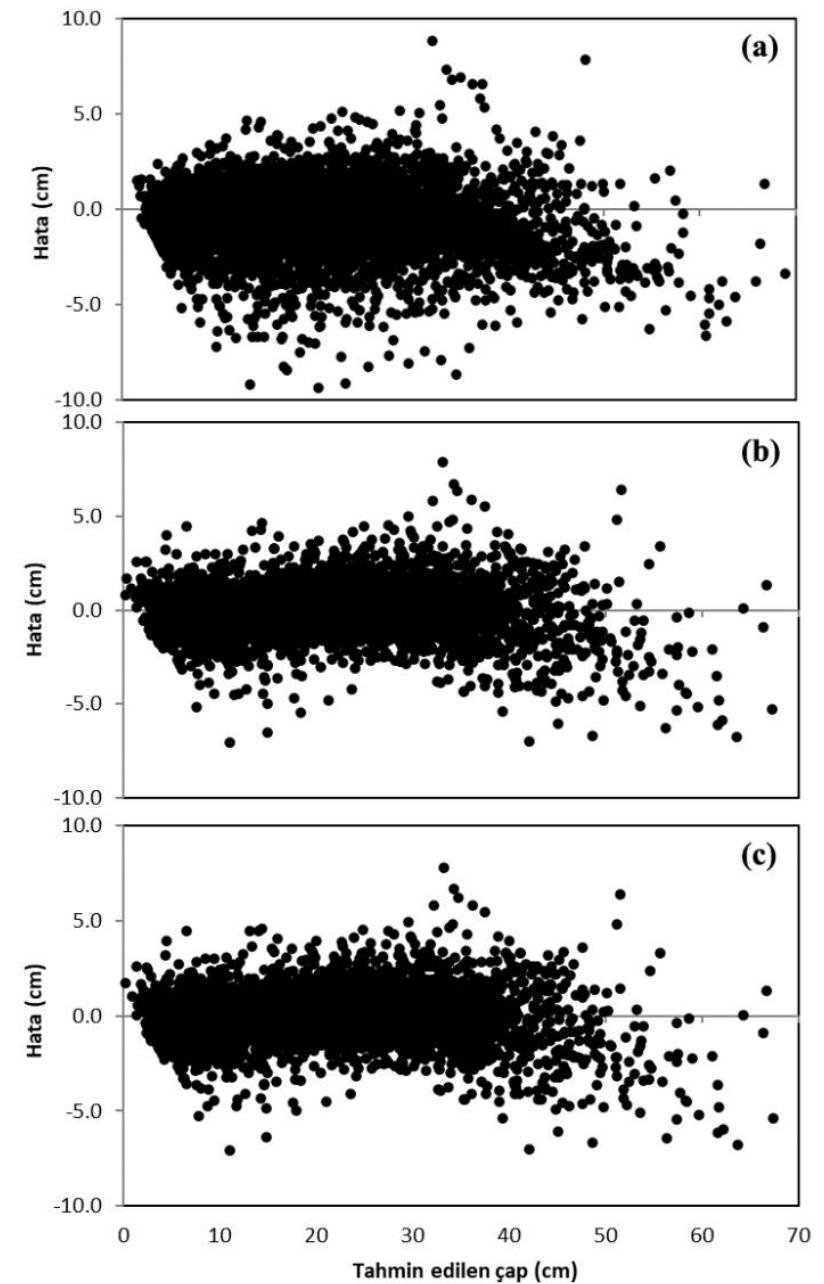

Şekil 3. ONLS (a), 3QR (b) ve 5QR (c) ile elde edilen gövde çapı tahminlerine ilişkin hata dağılımı

\section{Açıklama}

Bu çalıșmada kullanılan veriler, Türkiye Bilimsel ve Teknolojik Araştırma Kurumu (TÜBİTAK) tarafından maddi olarak desteklenen (Proje No: 109 O 714) proje ile elde edilmiştir. Arazi çalışmalarındaki yardımlarından dolayı Orman Genel Müdürlüğü çalışanlarına da teşekkür ederiz. Yazarlardan Şerife KALKANLI Sürdürülebilir Ormancılık tematik alanında 100/2000 YÖK doktora bursiyeridir.

\section{Kaynaklar}

Alkan, O., Özçelik, R., Alkan, H., 2019. Türkiye'nin bazı önemli ağaç türleri için yöresel gövde çapı modellerinin geliştirilmesi: Bucak örneği. Turkish Journal of Forestry, 20(4): 333-340.

Biging, G.S., 1984. Taper equations for second-growth mixed conifers of Northern California. Forest Science, 30(4): 1103-1117.

Bohora, S.B., Cao, Q.V., 2014. Prediction of tree diameter growth using quantile regression and mixed-effects models. Forest Ecology and Management, 319: 62-66.

Cao, Q.V., Burkhart, H.E., Max, T.A., 1980. Evaluation of two methods for cubic-volume prediction of loblolly pine to any merchantable limit. Forest Science, 26(1): 71-80.

Cao, Q.V., Wang, J., 2015. Evaluation of methods for calibrating a tree taper equation. Forest Science, 61(2): 213-219.

Castedo-Dorado, F., Gómez-García, E., Diéguez-Aranda, U., BarrioAnta, M., Crecente-Campo, F., 2012. Aboveground stand-level biomass estimation: a comparison of two methods for major forest species in northwest Spain. Annals of Forest Science, 69(6): 735746. 
Chen, C., Wei, Y., 2005. Computational issues for quantile regression. Sankhyā: The Indian Journal of Statistics, 67(2): 399417.

Clark, A., Souter, R.A., Schlaegel, B.E., 1991. Stem profile equations for southern tree species. Research paper SE (USA).

Coble, D.W., Hilpp, K., 2006. Compatible cubic-foot stem volume and upper-stem diameter equations for semi-intensive plantation grown loblolly pine trees in East Texas. Southern Journal of Applied Forestry, 30(3): 132-141.

Crecente-Campo, F., Alboreca, A.R., Diéguez-Aranda, U., 2009. A merchantable volume system for Pinus sylvestris L. in the major mountain ranges of Spain. Annals of forest science, 66(8): 808.

de-Miguel, S., Mehtätalo, L., Shater, Z., Kraid, B., Pukkala, T., 2012. Evaluating marginal and conditional predictions of taper models in the absence of calibration data. Canadian Journal of Forest Research, 42(7): 1383-1394.

Diéguez-Aranda, U., Castedo-Dorado, F., Álvarez-González, J.G., Rojo, A., 2006. Compatible taper function for Scots pine plantations in northwestern Spain. Canadian Journal of Forest Research, 36(5): 1190-1205.

Ducey, M.J., Knapp, R.A., 2010. A stand density index for complex mixed species forests in the northeastern United States. Forest Ecology and Management, 260(9): 1613-1622.

Evans, A.M., Finkral, A.J., 2010. A new look at spread rates of exotic diseases in North American forests. Forest Science, 56: 453-459.

Evans, A.M., Gregoire, T.G., 2007. A geographically variable model of hemlock woolly adelgid spread. Biological Invasions, 9(4): 369382 .

Fang, Z., Borders, B.E., Bailey, R.L., 2000. Compatible volume taper models for loblolly and slash pine based on system with segmented-stem form factors. Forest Science, 46: 1-12.

Farias, A.A., Soares, C.P.B., Leite, H.G., da Silva, G.F., 2021. Quantile regression: Prediction of growth and yield for a eucalyptus plantation in northeast Brazil. European Journal of Forest Research, 1-7.

Figueiredo-Filho, A., Borders, B.E., Hitch, K.L., 1996. Taper equations for Pinus taeda plantations in Southern Brazil. Forest Ecology and Management, 83(1-2): 39-46.

Gomez-Garcia, E., Fonseca, T.F., Crecente-Campo, F., Almeida, L.R., Dieguez-Aranda, U., Huang, S., Marques, C.P., 2015. Heightdiameter models for maritime pine in Portugal: a comparison of basic, generalized and mixed-effects models. iForestBiogeosciences and Forestry, 9(1): 72.

He, P., Hussain, A., Shahzad, M.K., Jiang, L., Li, F., 2021. Evaluation of four regression techniques for stem taper modeling of Dahurian larch (Larix gmelinii) in Northeastern China. Forest Ecology and Management, 494: 119336

Huang, Q., Zhang, H., Chen, J., He, M.J.J.B.B., 2017. Quantile regression models and their applications: A review. Journal of Biometrics \& Biostatistics, 8(3): 354.

Jiang, L., Brooks, J.R., Wang, J., 2005. Compatible taper and volume equations for yellow-poplar in West Virginia. Forest ecology and management, 213(1-3): 399-409.

Jiang, L. 2004. Compatible taper and volume equations for yellowpoplar in West Virginia. PhD Thesis, West Virginia University, Morgantown

Koenker, R., Bassett, G., 1978. Regression quantiles. Econometrica 46: 33-50.

Koenker, R., 2004. Quantile regression for longitudinal data. Journal of Multivariate Analysis, 91(1): 74-89.

Kozak, A., 2004. My last words on taper equations. The Forestry Chronicle, 80(4): 507-515.

Kozak, A., Munro, D.D., Smith, J.H.G., 1969. Taper functions and their application in forest inventory. The Forestry Chronicle, 45(4): 278283.

Kozak, A., Kozak, R., 2003. Does cross validation provide additional information in the evaluation of regression models?. Canadian Journal of Forest Research, 33(6): 976-987.

Ma, Y., Jiang, L., 2019. Stem taper function for Larix gmelinii based on nonlinear quantile regression. Scientia Silvae Sinicae, 55(10): 6875 .
Mäkinen, A., Kangas, A., Kalliovirta, J., Rasinmäki, J., Välimäki, E., 2008. Comparison of treewise and standwise forest simulators by means of quantile regression. Forest Ecology and Management, 255(7): 2709-2717.

Martin, A.J., 1981. Taper and volume equations for selected Appalachian hardwood species. Research Paper. NE-490. Broomall, PA: US Department of Agriculture, Forest Service, Northeastern Forest Experiment Station. 22p., 490.

Max, T.A., Burkhart, H.E., 1976. Segmented polynomial regression applied to taper equations. Forest Science, 22(3): 283-289.

Mehtätalo, L., Gregoire, T.G., Burkhart, H.E., 2008. Comparing strategies for modeling tree diameter percentiles from remeasured plots. Environmetrics: The Official Journal of The International Environmetrics Society, 19(5): 529-548.

OGM, 2019. Ormancilık İstatistikleri. https:/www.ogm.gov.tr/tr/ ormanlarimiz/resmi-istatistikler, Erişim: 18.06.2021.

Özçelik, R., Alkan, H., 2011. Okaliptüs ağaçlandırmaları için uyumlu gövde çapı ve gövde hacim modellerinin geliştirilmesi. I. Ulusal Akdeniz Orman ve Çevre Sempozyumu, 26-28 Ekim, Kahramanmaraş, s. 720-730

Özçelik, R., Crecente-Campo, F., 2016. Stem taper equations for estimating merchantable volume of Lebanon cedar trees in the Taurus Mountains, Southern Turkey. Forest Science, 62(1): 78-91

Özçelik, R., Cao, Q.V., Trincado, G., Göçer, N., 2018a. Predicting tree height from tree diameter and dominant height using mixed-effects and quantile regression models for two species in Turkey. Forest Ecology and Management, 419: 240-248.

Özçelik, R., Alkan, O., Korkmaz, M., 2018b. Local Volume Equations for Eucalyptus Plantations. International Congress on Agriculture and Animal Sciences, Kasim 7-9, Antalya, s. 383-396.

Özçelik, R., Diamantopoulou, M.J., Trincado, G., 2019. Evaluation of potential modeling approaches for Scots pine stem diameter prediction in north-eastern Turkey. Computers and Electronics in Agriculture, 162: 773-782.

Paulo, J.A., Firmino, P.N., Faias, S.P., Tomé, M., 2021. Quantile regression for modelling the impact of climate in cork growth quantiles in Portugal. European Journal of Forest Research, 1-14.

Rodriguez, F., Lizarralde, I., Fernández-Landa, A., Condés, S., 2014. Non-destructive measurement techniques for taper equation development: a study case in the Spanish Northern Iberian Range. European journal of forest research, 133(2): 213-223.

Rust, S., 2014. Analysis of regional variation of height growth and slenderness in populations of six urban tree species using a quantile regression approach. Urban Forestry \& Urban Greening, 13(2): 336-343.

Sharma, M., Parton, J., 2009. Modeling stand density effects on taper for jack pine and black spruce plantations using dimensional analysis. Forest science, 55(3): 268-282.

Sharma, M., Zhang, S., 2004. Height-diameter models using stand characteristics for Pinus banksiana and Picea mariana. Scandinavian Journal of Forest Research, 19(5): 442-451.

West, P.W., Ratkowsky, D.A., Davis, A.W., 1984. Problems of hypothesis testing of regressions with multiple measurements from individual sampling units. Forest Ecology and Management, 7(3): 207-224.

Xin, S., Jiang, L., 2020. Modeling stem taper profile for Pinus sylvestris plantations using nonlinear quantile regression. Journal of Beijing Forestry University, 42(2): 1-8.

Yang, Y., Huang, S., Trincado, G., Meng, S.X., 2009. Nonlinear mixed-effects modeling of variable-exponent taper equations for lodgepole pine in Alberta, Canada. European Journal of Forest Research, 128(4): 415-429.

Zang, H., Lei, X., Zeng, W., 2016. Height-diameter equations for larch plantations in northern and northeastern China: A comparison of the mixed-effects, quantile regression and generalized additive models. Forestry, 89(4): 434-445.

Zhang, L., Bi, H., Gove, J.H., Heath, L.S., 2005. A comparison of alternative methods for estimating the self-thinning boundary line. Canadian Journal of Forest Research, 35(6): 1507-1514. 